\title{
Value of screening for oro-pharyngeal Chlamydia trachomatis infection
}

\author{
S P R Jebakumar, C Storey, M Lusher, J Nelson, B Goorney, K R Haye
}

\begin{abstract}
Aims-To determine whether oro-pharyngeal colonisation by Chlamydia trachomatis occurs in patients at risk of genital chlamydia infection; to determine whether screening pharyngeal specimens by polymerase chain reaction (PCR) increases detection of $\boldsymbol{C}$ trachomatis compared with isolation and the immune dot blot test; and to correlate the detection of C trachomatis and Neisseria gonorrhoeae in the pharynx with a history of oro-genital contact.
\end{abstract}

Methods-Thirteen homosexuals and 11 heterosexuals were included in the study. Urogenital and pharyngeal specimens were tested for $C$ trachomatis and $N$ gonorrhoeae using standard clinical diagnostic procedures. Two different PCR methodologies were also used to detect $C$ trachomatis in the pharyngeal specimens. Results were correlated with the mode of sexual practice.

Results-Oro-genital sexual contact was practised by $64.9 \%(72 / 111)$ of heterosexuals in addition to penetrative penovaginal intercourse. Additionally, $62 \cdot 1 \%$ (77/124) of all patients did not use any form of barrier protection. Of those who admitted to oro-genital sexual contact, $17 \cdot 6 \%$ of patients with a genital chlamydial infection and $36.4 \%$ of those with genital gonorrhoea also had asymptomatic pharyngeal colonisation. C trachomatis was detected in three of $124(2 \cdot 4 \%)$ pharyngeal specimens by PCR which were reported as negative by chlamydial culture; one was positive by the immune dot blot test.

Conclusion-The majority of patients practised unprotected oro-genital contact and significant pharyngeal colonisation by $C$ trachomatis and $N$ gonorrhoeae occurred if genital infection was present. Despite the use of PCR in a population at high risk of sexually transmitted disease, the prevalence of chlamydia in the pharynx was very low. This indicates that transmission of $C$ trachomatis to the oropharynx does not pose a serious health risk and that screening of patients for oropharyngeal $C$ trachomatis is not worthwhile.

(f Clin Pathol 1995;48:658-661)

Keywords: Chlamydia trachomatis, Neisseria gonorrhoeae, oro-genital contact, PCR.

Since the advent of the HIV epidemic, sexually active heterosexual ${ }^{1}$ and homosexual ${ }^{2}$ popu- lations have apparently engaged more frequently in oro-genital contact. Urogenital infection with Chlamydia trachomatis is well recognised in these groups, but less is known about pharyngeal colonisation. A previous study from the USA showed a prevalence of pharyngeal chlamydial infection of $3.2 \%$ in women and $3 \cdot 7 \%$ in heterosexual men from a sexually transmitted disease (STD) clinic population. ${ }^{3}$ However, other reports have failed to recover any pharyngeal chlamydias from patients with asymptomatic ${ }^{4}$ or symptomatic pharyngitis. ${ }^{5}$ Studies carried out in the 1980 s, mainly in homosexual patients, recovered chlamydias from the pharynx of $1 \cdot 3 \%$ to $4 \cdot 3 \%^{7}$ of the patients studied, but it was not clear whether this low prevalence was genuine or due to insensitive diagnostic procedures.

We were encouraged by recent reports that chlamydias could be detected in the urogenital tract using polymerase chain reaction (PCR) when culture was negative. ${ }^{8-10}$ To date, there are no published studies on the use of PCR for the detection of $C$ trachomatis from extragenital sites apart from the eye. ${ }^{11}$ The aim of this study was to determine the prevalence of genital and pharyngeal colonisation by $C$ trachomatis and Neisseria gonorrhoeae in a group of patients attending a genito-urinary medicine clinic and to relate microbiological findings to the patients' mode of sexual practice. In addition to routine laboratory techniques, PCR was used to detect $C$ trachomatis in specimens from the pharyngeal mucosa.

\section{Methods}

A prospective study was carried out between 20 July 1992 and 15 January 1993 on 124 consecutive patients, aged between 13 and 35 years, attending the Department of GenitoUrinary Medicine at the Manchester Royal Infirmary (a provincial, inner-city clinic). This sample excluded patients who had taken antibiotics within the last three months. Any symptoms of sore throat, urethral or vaginal discharge, dysuria, urethral discomfort, or pelvic pain were noted. Patients were also requested to give information about protected/ unprotected sexual intercourse, oro-genital sexual contact and penetrative vaginal intercourse. A history of penetrative anal intercourse was only sought in male homosexuals.

COLLECTION AND STORAGE OF SPECIMENS Pharyngeal swabs

Three pharyngeal swabs were taken from each patient by rolling a sterile cotton wool tipped
Dorresponden $C$

Accepted for publication 3 November 1994 
swab over the tonsils and posterior pharynx. One was placed in 2SP-transport medium (TM) $\left(8 \mathrm{mM} \mathrm{KH}_{2} \mathrm{PO}_{4}, 12 \mathrm{mM} \mathrm{K}_{2} \mathrm{HPO}_{4}, 0 \cdot 2 \mathrm{M}\right.$ sucrose), one in PCR-TM $(0.4 \%$ SDS, $10 \mathrm{mM}$ Tris/ $\mathrm{HCl}(\mathrm{pH} \mathrm{8.4)})$ and the third in GC-TM (Thayers-Martins medium). The order in which the three swabs were taken was randomised.

\section{Urethral and endocervical swabs}

Two urethral swabs were taken from male patients; one was placed in 2SP-TM, the other in GC-TM. A urethral swab was taken from female patients and placed in GC-TM and, for chlamydial testing, urethral and endocervical swabs were obtained and placed in a single vial of 2SP-TM.

\section{Rectal swabs}

These were only collected from homosexual males. They were obtained under direct vision through a proctoscope by abrading the mucus. The swab was then placed in 2SP-TM.

Vaginal swabs

These were taken to test for Candida albicans and Trichomonas vaginalis.

\section{External genitalia}

External genitalia swabs for herpes simplex virus were taken if there was clinical evidence of infection.

\section{Serum}

Serum was obtained for syphilis serology.

Specimens in 2SP-TM were usually placed at $4^{\circ} \mathrm{C}$ and transported to the laboratory within 12 hours. If transport was delayed, they were stored in liquid nitrogen. Specimens in PCR$\mathrm{TM}$ were stored at $-70^{\circ} \mathrm{C}$ until analysis.

\section{ISOLATION OF CHLAMYDIA}

Chlamydial isolation was attempted using $0.2 \mathrm{ml}$ specimen in $2 \mathrm{SP}-\mathrm{TM}$ in McCoy cell monolayers by standard techniques. ${ }^{12}$ Chlamydial inclusions were detected by indirect immunofluorescence with a monoclonal antibody directed against the chlamydial lipopolysaccharide.

\section{IMMUNE DOT BLOT TEST}

This test was carried out as described by Storey et $a l^{13}$ using the modifications of Mearns et $a l^{14}$ in which $0.4 \mathrm{ml}$ specimen in 2SP-TM was digested with $250 \mu \mathrm{g} / \mathrm{ml}$ proteinase $\mathrm{K}$ for 60 minutes at $56^{\circ} \mathrm{C}$ then heated to $95^{\circ} \mathrm{C}$ for 15 minutes. The treated specimen was added to a nitrocellulose membrane in a dot blot manifold. The bound chlamydial lipopolysaccharide was then detected with an ${ }^{125} I$ labelled monoclonal antibody.

POLYMERASE CHAIN REACTION

Two PCR tests were used in this study. The first was an in-house test which targets a region of the chlamydial plasmid with the primers
CtC (5'-AAGATACGTGAATTCTTAAGTTCGGTC-3') and CtD (5'-TAATTGATCCAAACTCTGACTTTCCTC-3'). CtC hybridises to region 5331-5357 and $\mathrm{CtD}$ to region $5788-5762$ on the L2 plasmid, ${ }^{15}$ and produces a PCR product of 457 base pairs. This test is capable of detecting 10 elementary bodies and will detect all $C$ trachomatis serotypes.

Swabs in PCR-TM were vortexed for 30 seconds and then a $0.5 \mathrm{ml}$ sample was removed. This was digested with $250 \mu \mathrm{g} / \mathrm{ml}$ proteinase $\mathrm{K}$ at $56^{\circ} \mathrm{C}$ for 60 minutes. The samples were extracted once with phenol/chloroform, precipitated in ethanol, washed in $70 \%$ ethanol, and the DNA pellet resuspended in $30 \mu \mathrm{l}$ $10 \mathrm{mM}$ Tris/ $\mathrm{HCl}, 1 \mathrm{mM}$ EDTA (pH 8.0). Extracted samples were stored at $-40^{\circ} \mathrm{C}$. Ten per cent of all swabs processed were negative controls and contained PCR-TM and were to control for contamination of the samples with chlamydial DNA within the laboratory during processing. Each PCR reaction contained $0.2 \mu \mathrm{M}$ primer $\mathrm{CtC}, 0.2 \mu \mathrm{M}$ primer $\mathrm{CtD}$, $750 \mu \mathrm{M}$ dATP, dCTP, dGTP and dTTP, 1 unit of Taq polymerase, $67 \mathrm{mM}$ Tris $/ \mathrm{HCl}, 16.6 \mathrm{mM}$ $\left(\mathrm{NH}_{4}\right)_{2} \mathrm{SO}_{4}, 4 \mathrm{mM} \mathrm{MgCl}_{2}, 1 \mathrm{mg} / \mathrm{ml}$ bovine serum albumin, and $0.072 \%$ 2-mercaptoethanol. Five microlitres of extracted sample were tested in a reaction volume of $100 \mu$ l. DNA was amplified by one cycle of $94^{\circ} \mathrm{C}$ for seven minutes, $55^{\circ} \mathrm{C}$ for one minute and $72^{\circ} \mathrm{C}$ for one minute followed by 49 cycles of $94^{\circ} \mathrm{C}$ for one and a half minutes, $55^{\circ} \mathrm{C}$ for one minute and $72^{\circ} \mathrm{C}$ for one and a half minutes. PCR products were analysed using electrophoresis through $1 \%$ agarose gels and by a DNA hybridisation test. For this, $20 \mu \mathrm{l}$ of PCR product was denatured with $0.5 \mathrm{M} \mathrm{NaOH}, 0.5 \mathrm{M} \mathrm{NaCl}$ and then added to a nylon membrane in a slot blot manifold. The membrane was washed with $\times 20$ SSC $(\times 1$ SSC $=0.15 \mathrm{M} \mathrm{NaCl}, 0.015 \mathrm{M}$ $\mathrm{Na}_{3} \mathrm{C}_{6} \mathrm{H}_{5} \mathrm{O}_{7} .2 \mathrm{H}_{2} \mathrm{O}(\mathrm{pH} 7 \cdot 0)$ ) and with $\times 2 \mathrm{SSC}$, air dried and then the DNA was bound to the membrane by heating to $120^{\circ} \mathrm{C}$ for 20 minutes. Membranes were prehybridised in $0.25 \%$ skimmed mild powder in $\times 6 \mathrm{SSC}$ and then hybridised for 18 hours at $50^{\circ} \mathrm{C}$ with a 418 base pair fragment of the chlamydial plasmid (bases 5341-5759 ${ }^{15}$ ) labelled with ${ }^{32} \mathrm{P}$ dCTP. Membranes were washed sequentially in $\times 2$ SSC, $\times 0.5$ SSC and $\times 0.1$ SSC at $68^{\circ} \mathrm{C}$ and bound probe was detected using autoradiography.

The Amplicor $C$ trachomatis test (Roche Products Ltd) was also used. This commercial PCR also targets the chlamydial plasmid but uses different primers to those used in the inhouse test. PCR was carried out as described by the manufacturers.

\section{Results}

TOTAL GROUP

A total of 124 patients ( 62 men and 62 women) were evaluated. Thirteen of the male patients were homosexuals. Of the 124 patients, 77 $(62 \cdot 1 \%)$ did not use any form of barrier protection (condom or cervical cap) during penovaginal intercourse. 
Table 1 Comparison of diagnoses made in heterosexual patients with and without orogenital contact

\begin{tabular}{|c|c|c|c|c|}
\hline \multirow[b]{2}{*}{ Diagnosis } & \multicolumn{2}{|c|}{$\begin{array}{l}\text { Oro-genital contact in addition } \\
\text { to peno-vaginal intercourse }\end{array}$} & \multicolumn{2}{|c|}{ Peno-vaginal intercourse only } \\
\hline & Male $(n=32)$ & Female $(n=40)$ & Male $(n=17)$ & Female $(n=22)$ \\
\hline Genital chlamydia & 10 & 7 & 1 & 1 \\
\hline Pharyngeal chlamydia & 1 & 1 & 0 & 0 \\
\hline Genital gonorrhoea & 7 & 1 & 1 & 3 \\
\hline Pharyngeal gonorrhoea & 2 & 0 & 0 & 0 \\
\hline Non-specific urethritis & 4 & 0 & 0 & 0 \\
\hline Bacterial vaginosis & 0 & 4 & 0 & 5 \\
\hline Candidosis & 0 & 4 & 1 & 2 \\
\hline Genital warts & 5 & 6 & 2 & 2 \\
\hline Genital herpes & 0 & 1 & 2 & 1 \\
\hline Trichomonas vaginalis & 0 & 0 & 0 & 2 \\
\hline
\end{tabular}

\section{HETEROSEXUAL GROUP}

Seventy two of the $111(64 \cdot 9 \%)$ heterosexuals admitted having unprotected oro-genital sexual contact in addition to penetrative protected or unprotected peno-vaginal intercourse over the previous three months. The remainder had no history of oro-genital contact, but had had penetrative peno-vaginal intercourse over the same period of time. Table 1 compares the diagnoses in heterosexual patients who had had oro-genital contact with those who engaged in peno-vaginal intercourse only. $N$ gonorrhoeae was recovered from the urethra of three female and nine male patients. Twelve men and seven women had evidence of genital chlamydial infection when tested using the immune dot blot test and $C$ trachomatis was isolated from 12 of these patients (eight men and four women).

\section{HOMOSEXUAL GROUP}

All 13 homosexual men had unprotected orogenital contact in addition to penetrative (protected or unprotected) receptive anal intercourse. None of these men had evidence of genital chlamydial infection. $N$ gonorrhoeae was isolated from the urethra of two patients and the rectum of two patients.

\section{PHARYNGEAL CHLAMYDIA INFECTION}

Three pharyngeal samples were positive for chlamydias using the Roche PCR kit but were culture negative. Two of these were also positive by the in-house PCR and the remaining specimen was positive by the immune dot blot test (table 2). All specimens came from patients who had had oro-genital contact. Two were heterosexual females who also had concomitant genital chlamydial infection. The other patient with pharyngeal infection was a homosexual man with a history of oro-genital contact, but without any detectable chlamydia at other sites. However, chlamydia was isolated from the urethra of his partner. None of these patients had any symptoms of pharyngitis.

Table 2 Detection of pharyngeal chlamydiae in three patients

\begin{tabular}{lllllll}
\hline Gender & $\begin{array}{l}\text { Amplicor } \\
P C R\end{array}$ & $\begin{array}{l}\text { In-house } \\
\text { PCR }\end{array}$ & IDBT & Culture & $\begin{array}{l}\text { Genital } \\
\text { chlamydiae }\end{array}$ & $\begin{array}{l}\text { Unprotected } \\
\text { on-genital } \\
\text { contact }\end{array}$ \\
\hline Male homosexual* & + & + & - & - & - & Yes \\
Male heterosexual & + & + & - & - & + & Yes \\
Female heterosexual & + & - & + & - & + & Yes \\
\hline
\end{tabular}

* Partner had genital chlamydia; IDBT =immune dot blot test.
PHARYNGEAL GONORRHOEA

$N$ gonorrhoeae was isolated from four of the 124 pharyngeal specimens. Two of these were from heterosexual men with concomitant genital gonorrhoea and a history of oro-genital contact in addition to penetrative unprotected vaginal intercourse. The two other specimens were from male homosexuals who had unprotected oro-genital contact and unprotected penetrative anal intercourse associated with urethral gonorrhoea and rectal gonorrhoea (one patient). Gonorrhoea was isolated from the pharynx but not the urethra from the partner of one of these patients. Gonorrhoea was not isolated from the partner of the second homosexual patient. In the heterosexual population two of $12(16 \cdot 7 \%)$ patients with genital gonorrhoea also had pharyngeal colonisation by $N$ gonorrhoeae.

\section{Discussion}

It has been suggested that oro-genital contact can be an effective way of transmitting genital pathogens to the pharynx. ${ }^{316}$ However, the lack of correlation between symptomatic pharyngitis and pharyngeal colonisation by $C$ trachomatis and $N$ gonorrhoeae makes it difficult for the clinician to select patients from whom to take specimens for further investigation. This may be further confounded by the reluctance of many patients to give information regarding oro-genital contact.

Our study, which is the largest study into the incidence of pharyngeal chlamydial infection among heterosexuals undertaken in the United Kingdom, shows that a significant number of patients $(62 \cdot 1 \%)$ attending an inner-city, provincial Genito-Urinary Medicine Clinic did not use any form of protection, thus potentially exposing them to STDs and HIV infection. In addition, $64.9 \%$ of heterosexual patients and all homosexual patients were engaged in orogenital contact, at risk of exposing the pharyngeal mucosa to genital pathogens. Other studies have reported a similar prevalence of oro-genital sexual contact varying between $69 \cdot 4 \%^{17}$ and $73 \%{ }^{1}$.

Our findings show that $C$ trachomatis can be detected in the pharynx of sexually active persons by PCR. The number of positive samples was too low to permit a comparison of the three tests (immune dot blot test, Amplicor PCR, in-house PCR) and the different results could be due to sampling errors. However, all three pharyngeal specimens were positive by more than one test suggesting these are true positives despite being culture negative. All three pharyngeal specimens were from patients with a history of receptive unprotected orogenital contact. Two of these patients were heterosexual females and the other a homosexual man. Interestingly, no patients in whom chlamydia was detected in the pharynx complained of any symptoms from this site. In a previous study Bowie et $a l^{14}$ did not find any evidence that heterosexual women with a history of oro-genital contact were more likely to have a pharyngeal chlamydial infection than women who did not; however, our study sup- 
ports the finding of Jones $e t a l^{3}$ who found that such women were three times more likely to have a pharyngeal chlamydial infection.

The rate of transmission of chlamydia in this population is probably quite high; nearly a quarter of the heterosexuals who practised orogenital sexual contact had a genital chlamydial infection and so would potentially have passed viable chlamydia in their genital secretions to their partners' oro-pharynx. However, only $2 \cdot 8 \%$ had a detectable pharyngeal infection. The difficulty with which $C$ trachomatis was recovered from the oro-pharynx in this population indicates that large numbers of organisms are not found at this site, probably because the pharyngeal mucosa is not well suited to colonisation by $C$ trachomatis. There is some experimental evidence to support this; in chimpanzees a higher inoculum of chlamydia is needed to initiate a pharyngeal infection than a urethral infection. ${ }^{21}$

Pharyngeal colonisation by $N$ gonorrhoeae in our study occurred in $3.2 \%$ of patients, none of whom had symptoms of pharyngitis. This is comparable with other studies, which indicate a prevalence ranging from $2 \cdot 9 \%{ }^{3}$ to $11 \cdot 3 \% .{ }^{18} \mathrm{~A}$ unique feature of our study was that pharyngeal colonisation by $N$ gonorrhoeae was not observed in the female patients. In homosexual men a much higher prevalence of pharyngeal gonorrhoea (15.4\%; two of 13$)$ was observed in comparison with heterosexual men $(4 \cdot 1 \%)$. The pharyngeal strains were $\beta$-lactamase negative. All of these patients had a history of receptive unprotected oro-genital contact and evidence of concomitant gonorrhoea, either in the urogenital tract or rectum. Previously, BroJogensen and Jensen ${ }^{19}$ and Willmott ${ }^{20}$ have shown that mouth to mouth transfer and mouth to genital transfer can take place with $N$ gonorrhoeae.

Colonisation of the pharynx by $C$ trachomatis and $N$ gonorrhoea does occur if genital infection is also present among individuals who engaged in oro-genital contact. However, despite the use of PCR in a high risk STD clinic population the prevalence of chlamydia in the pharynx was very low. These observations should help clinicians council patients who engage in orogenital contact. The results indicate that transmission of $C$ trachomatis to the oro-pharynx does not pose a serious health risk and screening of patients, at risk of infection with genital chlamydias, for oro-pharyngeal $C$ trachomatis is not worthwhile.
We sincerely thank Dr S Richmond, Consultant Virologist, for helping to design the study and preparing the manuscript. Special thanks are also due to nursing and reception staff at the G.U.M. Clinic at Manchester Royal Infirmary, and Miss Sandra Bright and Mrs Carol Mather for secretarial assistance.

1 Moscicki AB, Millstein SG, Broering J, Irwin CE. Risks of human immunodeficiency virus infection among adolescents attending three diverse clinics. $\mathcal{F}$ Pediatr 1993; 122:813-20.

2 Bill JO, Tanfer K, Grady WR, Klepinger DH. The sexual behaviour of men in the United States. Fam Plann Perspect 1993;25:52-60.

3 Jones RB, Rabinovitch RA, Katz BP, Batteiger BE, Quin $\mathrm{TS}$, Terho $\mathrm{P}$, et al. Chlamydia trachomatis in the pharynx and rectum of heterosexual patients at risk of genital infection. Ann Intern Med 1985;102:757-62.

4 Bowie WR, Alexander ER, Holmes KK. Chlamydial pharyngitis? Sex Transm Dis 1977;4:140-1.

5 Gerber MA, Ryan R, Tilton RC, Watson JE. Role of Chlamydia trachomatis in acute pharyngitis in young adults. $\mathcal{F}$ Clin Microbiol 1984;20:993-4.

6 McMillan AR, Sommerville RG, McKie PMK. Chlamydial infection in homosexual men: frequency of isolation of Chlamydia trachomatis from urethera, ano-rectum, and pharynx. Br ₹ Vener Dis 1981;57:47-9.

pharynx. Br f Vener Dis 1981;57:47-9.
7 Sulaiman MZC, Foster J, Pugh SF. Prevalence of Chlamydia trachomatis infection in homosexual men. Genitourin Med trachomatis infectio

8 Drzonek HN, Wolf J, Doeberitz MVK, Petzoldt D. Detection of Chlamydia trachomatis in urogenital specimens by polymerase chain reaction. Genitourin Med 1991;67: 211-14.

9 Witkin SS, Jeremias J, Toth M, Ledger WJ. Detection of Chlamydia trachomatis by polymerase chain reaction in the cervices of women with acute salpingitis. Am 7 Obstet Gynecol 1993;168:1438-42.

10 Jaschek G, Gaydos CA, Welsh LE, Quinn TC. Direct detection of Chlamydia trachomatis in urine specimens from symptomatic and asymptomatic men by using a rapid polymerase chain reaction assay. $\mathcal{f}$ Clin Microbiol $1993 ; 31$ : polymerase

11 Bobo L, Monoz B, Viscidi R, Quinn T, Mkocha H, West $S$. Diagnosis of Chlamydia trachomatis eye infection in Tanzania by polymerase chain reaction/enzyme immunoassay. Lancet 1991;338:847-50.

2 Richmond SJ, Bailey JMG, Bailey AS, Mearns G. Primary isolation of Chlamydia trachomatis and Chlamydia psittaci in in vitro cell culture. In: Collins $\mathrm{CH}$, Grange JM, eds. Isolation and identification of micro-organisms of medical and veterinary importance. New York: Academic Press, 1985: veterinary

13 Storey C, Mearns G, Richmond SJ. Immune dot blot technique for diagnosing infection with Chlamydia trachnique for diagnosing infection with

14 Mearns G, Richmond SJ, Storey C. Sensitive immune dot blot test for diagnosis of Chlamydia trachomatis infection. f Clin Microbiol 1988;26:1810-13.

15 Comanducci M, Ricci S, Ratti G. The structure of a plasmid of Chlamydia trachomatis believed to be required for growth withim mammalian cells. Mol Microbiol 1988;2: 531-8

16 Sackel SG, Alpert S, Fiuamara NJ, Donner A, Laughlin CA, McCormack WM. Orogenital contact and the isolation of Neisseria gonorrhoeae, Mycoplasma hominis and Ureaplasma urealyticum from the pharynx. Sex Transm Dis 1979;6:64-8.

17 Evans BA, Tasker T, MacRae KD. Risk profiles for genital infection in women. Genitourin Med 1993;69:257-67.

18 Noble RC, Cooper RM, Miller BR. Pharyngeal colonisation by Neisseria gonorrhoeae and Neisseria meningitidis in by Neisseria gonorrhoeae and Neisseria meningitidis in Br $\mathcal{F}$ Vener Dis 1979;55:14-19.

19 Bro-Jorgensen A, Jensen T. Gonococcal pharyngeal infection: report of 110 cases. Br $\mathcal{F}$ Vener Dis 1973;49:491-2. 20 Willmott FE. Transfer of gonococcal pharyngitis by kissing? Br $\mathcal{F}$ Vener Dis 1974;50:317.

21 Jacobs NF, Arum ES, Kraus J. Experimental infection of the chimpanzee urethra and pharynx with Chlamydia trachomatis. Sex Transm Dis 1978;5:132-6. 